\title{
Correction to: Outlier removal in biomaterial image segmentations using a non-stationary Bayesian learning
}

\author{
Wahyudin P. Syam ${ }^{1,2} \cdot$ Panorios Benardos ${ }^{3} \cdot$ Emily Britchford $^{4} \cdot$ Andrew Hopkinson $^{4} \cdot$ David T. Branson III $^{1}$
}

Published online: 26 July 2021

○ The Author(s), under exclusive licence to Springer-Verlag London Ltd., part of Springer Nature 2021

\section{Correction to: Pattern Analysis and Applications https://doi.org/10.1007/s10044-021-00979-9}

In the original publication of the article, supplementary material link was included which was not provided by the author during the initial submission.

The ESM link has been removed in the original article.

The original article has been updated.

Publisher's Note Springer Nature remains neutral with regard to jurisdictional claims in published maps and institutional affiliations.

The original article can be found online at https://doi.org/10.1007/ s10044-021-00979-9.

Wahyudin P. Syam

wahyudin.syam@nottingham.ac.uk

1 Nottingham Advanced Robotic Laboratory (NARLy),

Faculty of Engineering, University of Nottingham,

NG8 1BB Nottingham, UK

2 Manufacturing Metrology Team, Faculty of Engineering, University of Nottingham, NG8 1BB Nottingham, UK

3 Section of Manufacturing Technology, School of Mechanical Engineering, National Technical University of Athens, GR15780 Zografou, Athens, Greece

4 NuVision Biotherapies Ltd, MediCity, D6 Building, Nottingham NG90 6BH, UK 